\title{
Rescue of retinal morphology and function in a humanized mouse at the mouse retinol-binding protein locus
}

\author{
Li Liư ${ }^{1,2}$, Tomohiro Suzuki ${ }^{3}$, Jingling Shen ${ }^{1}$, Shigeharu Wakana ${ }^{3}$, Kimi Araki $^{4}$, Ken-ichi Yamamura ${ }^{2}$, Lei Lei ${ }^{1}$ and \\ Zhenghua $\mathrm{Li}^{1,2}$
}

Retinol-binding protein RBP4 is the specific carrier for retinol in the blood. We previously produced a Rbp4-deficient $\left(R b p 4^{-/-}\right)$mouse that showed electroretinogram (ERG) abnormalities, accompanied by histological and electronmicroscopic changes such as fewer synapses in the inner plexiform layer in the central retina. To address whether human $R B P 4$ gene expression can rescue the phenotypes observed in $R b p 4^{-/-}$mice, we produced a humanized (Rbp4 ${ }^{\text {hRBP4orf/ } h R B P 4 \text { orf }}$ ) mouse with a human RBP4 open reading frame in the mouse Rbp4 locus using a Cre-mutant lox recombination system. In $R b p 4^{h R B P 4 o r f / h R B P 4 \text { orf }}$ mice, the tissue-specific expression pattern of $h R B P 4$ orf was roughly the same as that of mouse Rbp4. ERG and morphological abnormalities observed in $\mathrm{Rbp}^{-/-}$mice were rescued in $R b p 4^{h R B P 4 \text { orf/hRBP4orf }}$ mice as early as 7 weeks of age. The temporal expression pattern of $h R B P 4$ orf in the liver of $R b p 4^{h R B P 4 o r f / h R B P 4 o r f}$ mice was similar to that of mouse $R b p 4$ in $R b p 4^{+/+}$mice. In contrast, $h R B P 4$ orf expression levels in eyes were significantly lower at 6 and 12 weeks of age compared with mouse Rbp4 but were restored to the control levels at 24 weeks. The serum hRBP4 levels in $R b p 4^{h R B P 4 o r f / h R B P 4 o r f}$ mice were approximately $30 \%$ of those in $R b p 4^{+/+}$at all ages examined. In accordance with this finding, the plasma retinol levels remained low in Rbp4 ${ }^{\text {hRBP4orf } / h R B P 4 o r f}$ mice. Retinol accumulation in the liver occurred in control and $R b p 4^{\text {hRBP4orf/hRBP4orf }}$ mice but was higher in $R b p 4^{\text {hRBP4orf/hRBP4orf }}$ mice at 30 weeks of age. Mouse transthyretin expression was not altered in $R b p 4^{-/-}$or $R b p 4^{\text {hRBP4orf/hRBP4orf }}$ mice. Taken together, $30 \%$ of the serum RBP4 level was sufficient to correct the abnormal phenotypes observed in $R b p 4^{-/-}$mice.

Laboratory Investigation (2017) 97, 395-408; doi:10.1038/labinvest.2016.156; published online 30 January 2017

The retinol-binding protein 4 ( $h R B P 4$ for human and $m R b p 4$ for mouse) gene consists of six exons and five introns. ${ }^{1,2}$ RBP4 is a single polypeptide chain with a molecular weight of approximately $21 \mathrm{kDa}$ and has one binding site for retinol. RBP4 is synthesized primarily in the liver ${ }^{1,3}$ and in other sites, including the kidney, ${ }^{3}$ the peritubular and Sertoli cells of the testis, ${ }^{4,5}$ the retinal pigment epithelium, ${ }^{6,7}$ and the choroid plexus of the brain ${ }^{8}$ (for a review, see Soprano and Blaner ${ }^{8}$ ). Vitamin A, absorbed from the intestine in the form of retinyl esters, is taken up by the liver; thus, the liver serves as the primary storage depot for vitamin A. ${ }^{9}$ In hepatocytes RBP4 associates with retinol, moves to the Golgi apparatus and is secreted into blood. ${ }^{8}$ In other words, retinol is mobilized from liver stores by binding to RBP4. Thus, retinol is deposited in the absence of RBP4. Vitamin A, in the form of retinal, is necessary for both low-light (scotopic vision) and color vision in the retina of the eye by binding with the protein opsin to form rhodopsin. ${ }^{10}$

In human patients with no detectable plasma RBP4 due to RBP4 gene mutations, various phenotypes, such as an iris coloboma, atrophy or focal loss of the retinal pigment epithelium (RPE) and the choroid, and reduced scotopic and photopic electro-retinograms (ERGs), have been reported. ${ }^{11,12}$ Quadro et al ${ }^{13}$ produced $R b p 4^{-1-}$ mice in a mixed genetic background $(129 \mathrm{xC} 57 \mathrm{BL} / 6 \mathrm{~J})$ and found that these mice had impaired visual function, as evidenced by abnormal ERG. The mice had decreased sensitivity to light at only the b-wave amplitude, with progressive improvement such that this sensitivity approached that of wild-type mice by 24 weeks of age. Quadro et al ${ }^{13,14}$ also generated a transgenic

${ }^{1}$ Department of Histology and Embryology, Harbin Medical University, Harbin, Heilongjiang, China; ${ }^{2}$ Yamamura Project Laboratory, Institute of Resource Development and Analysis, Kumamoto University, Kumamoto, Kumamoto, Japan; ${ }^{3}$ Technology and Development Team for Mouse Phenotype Analysis, RIKEN BioResource Center, Tsukuba, Ibaraki, Japan and ${ }^{4}$ Division of Developmental Genetics, Institute of Resource Development and Analysis, Kumamoto University, Kumamoto, Kumamoto, Japan Correspondence: Professor L Lei, PhD, or Professor Z Li, MD, PhD, Department of Histology and Embryology, Harbin Medical University, Harbin, Heilongjiang, China. E-mail: leiys2002@yahoo.com or liseika@kumamoto-u.ac.jp

Received 13 July 2016; revised 7 December 2016; accepted 12 December 2016 
mouse strain (hRBP4: $\mathrm{mRbp}^{-/-}$) that expressed $\mathrm{hRBP4}$ under the control of the muscle creatine kinase promoter in the $R b p 4^{-1-}$ background. Although no hRBP4 was detected in the retinal pigment epithelium of hRBP4:mRbp4 $4^{-/-}$mice, a normal ERG profile and normal retinol levels were observed in the eyes. To examine whether similar phenotypes were observed in the C57BL/6 background, we previously produced Rbp4-deficient $\left(R b p 4^{-/-}\right)$mice. ${ }^{15}$ These $R b p 4^{-/-}$mice had decreased a- and b-wave amplitudes on scotopic ERGs. In accordance with these abnormalities, we found structural changes in these mice, such as the loss of the choroid and photoreceptor layers in the peripheral retina. In the central retina, the distance between the inner limiting membrane and the outer plexiform layer was much shorter with fewer ganglion cells and fewer synapses in the inner plexiform layer. Thus, $R b p 4^{-/-}$mice had similar phenotypes as in human patients.

The RBP4-retinol complex binds to the transthyretin (TTR) tetramer in hepatocytes, and this complex is then secreted into the serum. ${ }^{16-19}$ This binding is important for both TTR and RBP4 because it stabilizes the TTR tetramer and prevents the renal filtration of RBP4. ${ }^{9}$ As the dissociation of the TTR tetramer is a critical step in amyloid deposition, the binding affinity between TTR and RBP4 is an important factor towards the dissociation of the TTR tetramer. Therefore, it is essential to have both human TTR (hTTR) and human RBP4 (hRBP4) in the same mouse model to mimic the human environment.

To establish double-humanized mice at both the Ttr and Rbp4 loci as the final goal, we previously produced a Ttrdeficient mouse and a humanized mouse (Ttr ${ }^{h T T R o r f h T T R o r f}$ ) carrying the $h T T R$ open reading frame (hTTRorf) in the mouse Ttr (mTtr) locus using a Cre-mutant lox

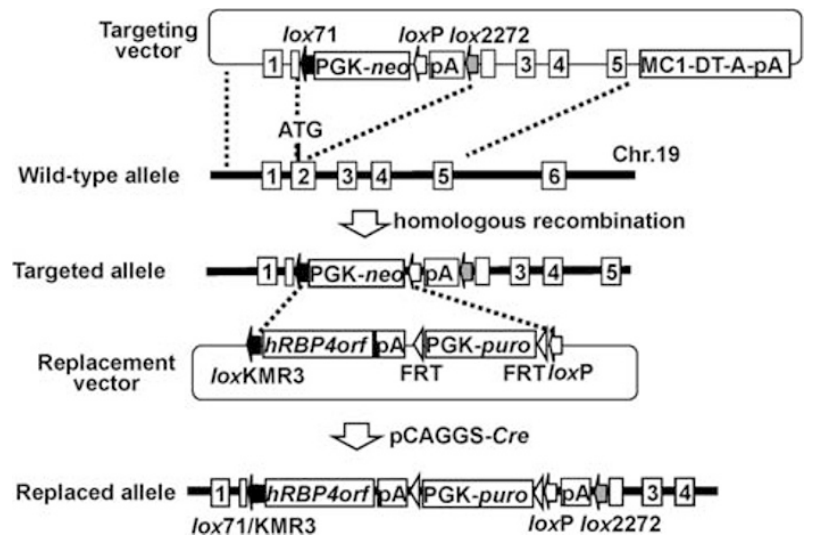

Figure 1 Creation of targeted and replaced alleles. Homologous recombination between the wild-type allele and the targeting vector yielded a targeted null allele carrying the PGK-neo gene flanked by lox71 and loxP. In the second step, targeted clones were electroporated with the replacement vector carrying the hRBP4orf flanked by loxKMR3 and loxP. Site-directed recombination between lox71/loxKMR3 and loxP/loxP resulted in the creation of the replaced allele. recombination system. ${ }^{20}$ Using the same method, Rbp4deficient mice have been produced. ${ }^{15}$ Here, a human $R B P 4$ open reading frame ( $h R B P 4$ orf) was inserted into the mouse $R b p 4$ ( $m R b p 4$ ) locus using these embryonic stem (ES) clones. Subsequently, humanized mice at the Rbp4 locus $\left(R b p 4^{h R B P 4 o r f / h R B P 4 o r f}\right)$ were established. We examined whether phenotypes observed in $R b p 4^{-/-}$mice could be rescued by $h R B P 4$ expression in $R b p 4^{h R B P 40 r f / h R B P 4 o r f}$ mice. Here, we show that the retinal function and morphological defects observed in $R b p 4^{-/-}$mice are rescued in $R b p 4^{h R B P 4 o r f / h R B P 4 o r f}$, although the serum hRBP4 is approximately $30 \%$ of that of the endogenous mRBP4. This information will be valuable for estimating the expression level required to maintain function and to restore phenotypes in human genetic diseases.

\section{MATERIALS AND METHODS \\ Construction of Targeting/Replacement Vectors and the Isolation of Targeted/Replaced ES Cells Carrying hRBP4orf}

The construction of targeting vector and the isolation of targeted ES cells were achieved using a similar method as described previously. ${ }^{20}$ Briefly, a $2.8 \mathrm{~kb} 5^{\prime} \mathrm{Rbp} 4$ homologous region upstream of the ATG codon and a $6.7 \mathrm{~kb} 3^{\prime} R b p 4$ homologous region downstream of the ATG codon were ligated with a p71neoP cassette that contained lox71-PGK$n e o^{R}$-loxP-polyA-lox2272 to produce the Rbp4-71neo ${ }^{\mathrm{R}}$-Rbp4 construct that comprised the $5^{\prime} R b p 4$ homologous regionlox71-PGK-neo ${ }^{R}$-loxP-polyA-lox2272-3' Rbp4 homologous region. Finally, a diphtheria toxin A (DT-A) fragment with an $\mathrm{MC} 1$ promoter was ligated to the $3^{\prime}$ end of $3^{\prime} \mathrm{Rbp} 4$ homologous region to produce the targeting vector (Figure 1). The targeting vectors were introduced into TT2 ES cells ${ }^{21}$ derived from an F1 embryo that resulted from a mating between C57BL/6 and CBA mice (Charles River, Yokohama, Japan).

For the construction of the replacement vector, we first made a cassette that contained ahRBP4 cDNA, and a puromycin resistance gene with a phosphoglycerokinase promoter (PGK-puro) flanked by two Flp recognition target (FRT) sequences. Then, the cassette flanked by loxKMR3 and loxP sites was inserted into pSP73 (Promega, Tokyo, Japan). The ES cell lines with the Rbp4 targeted null allele were coelectroporated (Bio-Rad Gene Pulser at $400 \mathrm{~V}, 125 \mu \mathrm{F}$ ) with $20 \mu \mathrm{g}$ of the replacement vector plasmid and $20 \mu \mathrm{g}$ of the pCAGGS-Cre $e^{22}$ to produce ES clones with the replaced allele.

\section{Southern Blot Analyses for the Isolation of Targeted and Replaced ES Clones}

The replaced ES clones were screened and confirmed by Southern blot analyses using genomic DNA obtained from ES cells according to the methods described previously. ${ }^{20}$ For the detection of homologous recombination in the $5^{\prime}$ region, DNA from ES cells was digested with XhoI/SalI or MunI and analyzed for the presence of the targeted allele using a neo and 
$5^{\prime}$ probes (Supplementary Figure S1). For the detection of homologous recombination in the $3^{\prime}$ region, DNA from ES cells was digested with AgeI/HpaI or SacII/HpaI and analyzed for the presence of the targeted allele using a neo and $3^{\prime}$ probe (Supplementary Figure S1). For the detection of the replaced allele, genomic DNA from ES cells was digested with BamHI or BglII and was used for Southern blot analysis with a puromycin-specific probe (Supplementary Figure S1).

\section{Generation of RBP4orf Knock-in Mice}

Chimeric mice were produced by the aggregation of ES cells with eight-cell embryos from ICR mice according to the methods described previously. ${ }^{20}$ Chimeric male mice were backcrossed to C57BL/6 females (Clea Japan, Tokyo, Japan) for seven generations including marker-assisted breeding using 123 polymorphic markers (111 markers on autosomes, eight markers on the $\mathrm{X}$ chromosome and four markers on the Y chromosome; Japan Mouse Clinic: http://ja.brc.riken.jp/ lab/jmc/mouse_clinic/en/assistive/index.html) in the second and sixth generations. These mice had C57BL/6-homozygous alleles at all 123 polymorphic loci. The mice were fed a CE-2 diet (Clea Japan) which contained $1515 \mathrm{IU}$ retinol/100 g $(0.454 \mathrm{mg} / 100 \mathrm{~g})$. To avoid possible sex-related differences, only males were used in all the analyses. The experimental protocols that involved animals were approved by the Kumamoto University Ethics Committee for Animal Experiments (F25-329, F27-122) and all the experiments were performed in accordance with the institute's guidelines.

\section{Northern Blot, Semiquantitative RT-PCR and Quantitative RT-PCR Analyses}

Total RNA was isolated from the brain, whole eyes, heart, lung, small intestine, testis, skeletal muscle, liver, and kidney. Northern blot and semiquantitative reverse transcriptionpolymerase chain reaction (RT-PCR) analyses were performed according to the methods described by Zhao et al ${ }^{20}$ and $\mathrm{Li}$ et al, ${ }^{23}$ respectively. The nucleotide sequence identity between the mouse and human Rbp4-coding regions is $\sim 87 \%$. The primer set suitable for human and mouse RBP4coding regions was as follows: sense (mhRBP4-F), 5'-GAG TCAAGGAGAACTTCGAC-3'; and antisense (mhRBP4-e4R), 5'-CAGTACTTCATCTTGAACTTGG-3'; the PCR product was expected to be $244 \mathrm{bp}$ long. The primer set used for the detection of the Hprt mRNA was as follows: sense, $5^{\prime}$-CAC AGGACTAGAACACCTGC-3'; antisense, 5'-GCTGGTGAAA AGGACCTCT- $3^{\prime}$; the PCR product was expected to be $238 \mathrm{bp}$ long. PCR products were separated on $1.5 \%$ agarose gels and stained with ethidium bromide. Quantitative RT-PCR (qRT-PCR) was performed with an Applied Biosystems 7500 Real-Time PCR system (Applied Biosystems, Foster City, CA, USA). The reactions were performed under the following conditions: $1 \mathrm{~min}$ at $95^{\circ} \mathrm{C}$; followed by 40 cycles of $15 \mathrm{~s}$ at $95^{\circ} \mathrm{C}$ and $1 \mathrm{~min}$ at $60^{\circ} \mathrm{C}$. Quantified values were normalized against the input determined by the expression of the housekeeping gene Hprt.

\section{Functional Analysis of the Retina}

ERG was performed as previously described. ${ }^{24}$ The left eyes of $\mathrm{Rbp}^{+/+}, \mathrm{Rbp}^{-/-}$and Rbp4 $4^{h R B P 40 \text { rff } h R B P 40 \text { rf }}$ mice at 7, 14, 24, and 40 weeks of age were used. The mice were dark-adapted overnight and anesthetized with a mixture of ketamine (80 mg/kg; Daiichi Sankyo Propharma, Tokyo, Japan) and xylazine (16 mg/kg; Bayer Medical, Tokyo, Japan) under dim red light. The pupils were dilated with Mydrin-P ophthalmic solution (1:5 dilution), and the corneas were anesthetized with $0.4 \%$ oxybuprocaine hydrochloride (Santen Pharmaceutical, Tokyo, Japan). Stimulus presentation was programmed and data acquisition was performed using data recording and analysis software (Scope v.3.7; ADInstruments Pty, New South Wales, Australia). Scotopic ERG responses to single flash presentations (10 $\mathrm{ms}$ duration) at three increasing intensities $\left(2.0 \log \mathrm{cd} \mathrm{s} / \mathrm{m}^{2}\right)$ were recorded. Triplicate responses were computer-averaged for each flash condition. The time intervals between flashes were 10,30 , and $60 \mathrm{~s}$ for intensities of $2.0 \log \mathrm{cd} \mathrm{s} / \mathrm{m}^{2}$, respectively. The amplitude and implicit time of the a-wave were measured from the prestimulus baseline to the a-wave trough. The amplitude and implicit time of the b-wave were measured from the a-wave trough to the peak of the b-wave or, if the a-wave was not measurable, from the prestimulus baseline.

\section{Retinal Histology}

Mice at 7 and 40 weeks of age were anesthetized with an intraperitoneal injection of pentobarbital sodium $(90 \mathrm{mg} / \mathrm{kg}$; Kyoritsu Seiyaku, Tokyo, Japan). The eyes were fixed with $2 \%$ paraformaldehyde (PFA) and $2 \%$ glutaraldehyde (GA) in $0.1 \mathrm{M}$ cacodylate buffer $\mathrm{pH} 7.4$ at $4{ }^{\circ} \mathrm{C}$ overnight, washed three times with $0.1 \mathrm{M}$ cacodylate buffer for $30 \mathrm{~min}$ each, and postfixed with $2 \%$ osmium tetroxide $\left(\mathrm{OsO}_{4}\right)$ in $0.1 \mathrm{M}$ cacodylate buffer at $4{ }^{\circ} \mathrm{C}$ for $2 \mathrm{~h}$. The samples were then dehydrated in a graded ethanol series: 50 and $70 \%$ for $30 \mathrm{~min}$ each at $4{ }^{\circ} \mathrm{C}, 90 \%$ for $30 \mathrm{~min}$ at room temperature, three changes of $100 \%$ for $30 \mathrm{~min}$ each at room temperature and $100 \%$ ethanol overnight at room temperature. The samples were infiltrated with propylene oxide (PO) twice for $30 \mathrm{~min}$ each and were placed into a 70:30 mixture of PO and Quetol812 resin (Nisshin EM, Tokyo, Japan) for $1 \mathrm{~h}$; the tubes were kept open overnight to evaporate the PO. The samples were transferred to fresh $100 \%$ resin and polymerized at $60^{\circ} \mathrm{C}$ for $48 \mathrm{~h}$. The polymerized resins were semi-thin-sectioned at $1.5 \mathrm{~mm}$ with glass knives using an ultramicrotome (Ultracut UCT; Leica, Vienna, Austria) and were stained with $0.5 \%$ Toluidine blue.

\section{Measurement of Retinal Properties}

The distance from the retinal surface to the end of the photoreceptor outer segments was measured as the retinal thickness. The thicknesses of the INL, the ONL, and the photoreceptor OS in the central retina were measured by light microscopy at the point where the ratio of the distance from the optic disc to the point to the distance from the optic disc 
to peripheral end of the retina was $0.2{ }^{24}$ The values recorded for each parameter for the nasal and temporal sides were averaged to obtain a single value for each eye. For consistency, only retinal sections with optic nerve stumps were used.

\section{Transmission Electron Microscopy}

Mice at 7 and 40 weeks of age were used for this study. The eyes were fixed as described above at $4{ }^{\circ} \mathrm{C}$ overnight, washed three times with $0.1 \mathrm{M}$ cacodylate buffer for $30 \mathrm{~min}$ each, and postfixed with $2 \%$ osmium tetroxide in $0.1 \mathrm{M}$ cacodylate buffer at $4{ }^{\circ} \mathrm{C}$ for $2 \mathrm{~h}$. The samples were then dehydrated in a graded ethanol series: 50 and $70 \%$ for $30 \mathrm{~min}$ each at $4{ }^{\circ} \mathrm{C}$, $90 \%$ for $30 \mathrm{~min}$ at room temperature, three changes of $100 \%$ for $30 \mathrm{~min}$ each at room temperature and $100 \%$ ethanol overnight at room temperature. The samples were infiltrated with propylene oxide (PO) twice for $30 \mathrm{~min}$ each and then placed into a 70:30 mixture of PO and Quetol-812 resin (Nisshin EM) for $1 \mathrm{~h}$; the tube was kept open overnight to evaporate the PO. The samples were transferred to fresh $100 \%$ resin and polymerized at $60^{\circ} \mathrm{C}$ for $48 \mathrm{~h}$. Ultra-thin sections $(70 \mathrm{~nm})$ were cut with a diamond knife using an ultramicrotome (Ultracut UCT) and mounted on copper grids. They were stained with $2 \%$ uranyl acetate at room temperature for $15 \mathrm{~min}$, washed with distilled water, and
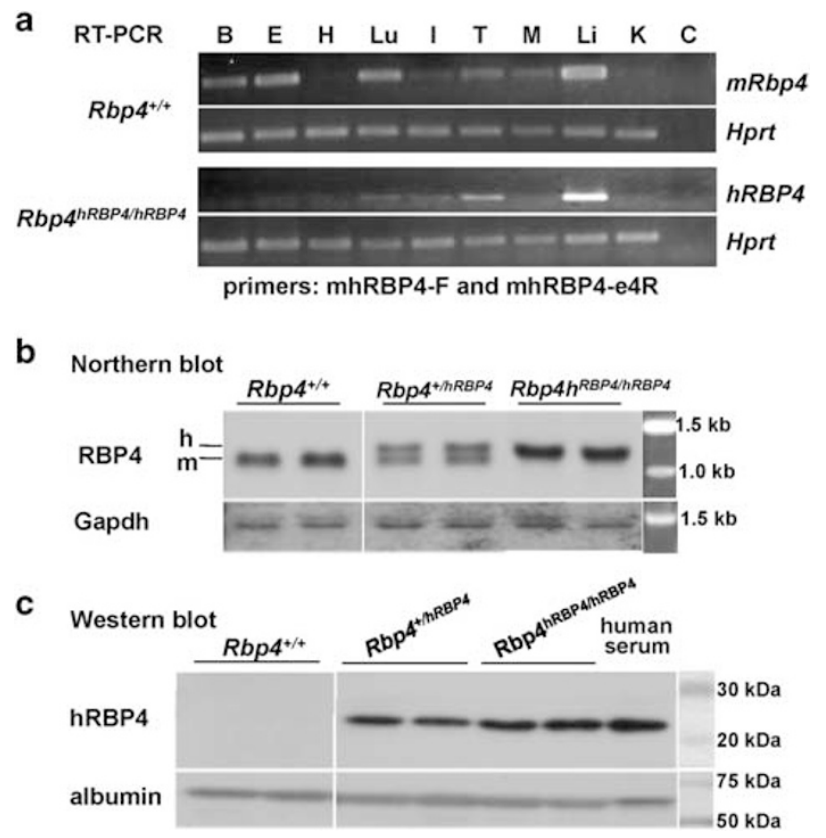

Figure 2 Tissue-specific and quantitative hRBP4 expression. (a) Tissue specificity of mRbp4 and hRBP4 mRNA expression. mRbp4 and hRBP4 were both expressed in various tissues, mainly in the liver, testis, and lung. (b) Northern blot analysis. The $h R B P$ level in $R b p 4^{h R B P 4 / h R B P 4}$ mice was approximately double that in $R b p 4^{+/ h R B P 4}$ mice. (c) Western blot analysis. The serum hRBP4 level in Rbp4 $4^{h B P A / h R B P 4}$ mice was approximately double that in $R b p 4^{+/ h R B P 4}$ mice. Before loading, sera from $R b p 4^{+/+}, R b p 4^{+/ h R B P 4}$, and Rbp4 ${ }^{\mathrm{hRBP} 4 / \mathrm{hRBP} 4}$ mice were diluted 10 times and human serum was diluted 50 times. $B$, brain; $E$, eye; $H$, heart; Lu, lung; I, intestine; $T$, testis; M, skeletal muscle; Li, liver; K, kidney; C, control; $h$, human; m, mouse. stained with lead staining solution (Sigma-Aldrich, Tokyo, Japan) at room temperature for $3 \mathrm{~min}$. The grids were examined under a transmission electron microscope (JEM-1400Plus; JEOL, Tokyo, Japan) at an acceleration voltage of $80 \mathrm{kV}$. Digital images $(2048 \times 2048$ pixels $)$ were taken with a CCD camera (Veleta; Olympus Soft lmaging Solutions $\mathrm{GmbH}$, Münster, Germany).

\section{Determination of Plasma and Liver Retinol Concentrations}

Plasma and liver retinol concentrations were measured when the mice were 8 and 30 weeks of age. The plasma retinol concentration was determined by SRL (Tokyo, Japan) according to the method described previously. ${ }^{25}$ The liver retinol was determined by Japan Food Research Company (Fukuoka, Japan) according to the method described previously. ${ }^{26}$ Briefly, the samples were saponified in a basic ethanol-water solution, neutralized, and diluted, which converted retinol esters to retinol. Retinol levels were quantified using high-performance liquid chromatography. As the protocol involves the saponification of retinyl esters, retinyl esters are converted to retinol. Thus, the amount of retinol is expressed as the total retinol.

\section{Protein Extraction from Liver}

The liver was homogenized in a RIPA lysis buffer system (sc24948, Santa Cruz, Biotechnology, Dallas, TX, USA). The homogenate was transferred to centrifuge tubes and the samples centrifuged at $10000 \mathrm{~g}$ for $20 \mathrm{~min}$ at $4{ }^{\circ} \mathrm{C}$. The protein concentrations were measured by using the BCA Protein Assay Kit (T9300A, Takara Bio, Shiga, Japan).

\section{Serum and Liver RBP4 Levels}

Commercial ELISA kits were used according to the manufacturers' instructions to determine serum and liver concentrations of mRBP4 (Mouse Retinol-Binding protein 4 ELISA Kit SimpleStep, ab202404, Abcam, Tokyo, Japan) and hRBP4 (AG-45A-0035YEK-KI01, AdipoGen, San Diego, CA, USA).

\section{Western Blot Analysis}

Mouse serum ( $5 \mu$ l diluted $1: 10$ in $0.9 \% \mathrm{NaCl}$ per lane) or liver extracts ( $60 \mu \mathrm{g}$ of protein per lane) were applied to a $10-20 \%$ gradient polyacrylamide gel and transferred to an Immobilon polyvinylidene difluoride membrane (Millipore, Billerica, MA, USA). The following primary antibodies were used: rabbit anti-human RBP4 antibody (diluted 1:1000; ab73022, Abcam for Figure 2c and 11774-1-AP, Proteintech, Rosemont, IL, USA for Figure 10), rabbit anti-mouse TTR antibody (diluted 1:1000; Thermo Fisher Scientific K.K., Yokohama, Japan), anti- $\beta$ actin antibody (diluted 1:10 000; Gene Tex, Tokyo Japan), and rabbit anti-bovine serum albumin antibody (diluted 1:1500; Merck Millipore, Tokyo, Japan). An anti-rabbit immunoglobulin G conjugated with horseradish peroxidase (Amersham Biosciences, Piscataway, 
NJ, USA) was used for detection. Recombinant MTTR protein (LSBio, Seattle, WA, USA) was used for the measurement of serum mTTR levels. Band intensities were quantified using ImageJ ver. 1.38 software (http://rsb.info.nih.gov/ij/docs/ index.html).

\section{Gel Filtration Chromatography for the Separation of RBP4-TTR Complexes}

Plasma $(0.1 \mathrm{ml})$ was loaded onto a Superdex 200 Increase 10/300 GL (GE Healthcare, Tokyo, Japan) column connected to an LC-8020 HPLC system (Toso, Tokyo, Japan). Protein complexes were separated by passing phosphatebuffered saline through at $0.5 \mathrm{ml} / \mathrm{min}$ for $50 \mathrm{~min}$ at room temperature. Eluted proteins were detected by their absorbance at $280 \mathrm{~nm}$ and collected in $0.5 \mathrm{ml}$ fractions for western blot analysis.

\section{Genotyping of the Crb1 Locus}

DNA samples isolated from tail biopsies were amplified separately for wild-type allele and mutant rd8 alleles using the methods described previously. ${ }^{27,28}$ The sizes of the amplified DNA of the wild-type and $r d 8$ alleles are 220 and $244 \mathrm{bp}$, respectively.

\section{Number of Mice Used for Each Experiment}

The number of mice used for each experiment is shown in Supplementary Table 2.

\section{Statistical Analysis}

At least three independent experiments were performed. Unpaired Student's $t$-tests were used for the statistical analysis. The results are expressed as the means \pm s.d. $P<0.05$ was considered to indicate a significant difference.

\section{RESULTS}

\section{Establishment of ES Clones and Mouse Strains with the} Replaced hRBP4orf Allele

The production of a targeted null allele for the Rbp4 locus and $R b p 4^{-/-}$mice by homologous recombination in ES cells was reported previously. ${ }^{15}$ Replacement vectors containing hRBP4orf and the Cre expression vector were electroporated into the targeted ES clones (Figure 1). Five of nine puromycin-resistant clones yielded 3.6 or $3.0 \mathrm{~kb}$ bands when digested with BamHI or BglII, respectively, in Southern blot analysis using the puromycin probe (Supplementary Figure S1). These clones were found to encode the replaced allele. Three ES clones (Nos. 2, 12, and 16) showed germline transmission (Supplementary Table S1). Homozygous humanized mice $\left(R b p 4^{h R B P 4 o r f / h R B P o r f}\right)$ were used in subsequent experiments. Both $R b p 4^{-/-}$and $R b p 4^{h R B P 4 o r f / h R B P o r f}$ adults were viable and fertile under a diet of $1515 \mathrm{IU}$ retinol/ $100 \mathrm{~g}$ food.

\section{Tissue-Specific and Quantitative hRBP4 Expression}

To examine the tissue-specific expression of mouse Rbp4 (mRbp4) and hRBP4, RNA was extracted from various tissues and analyzed by semiquantitative RT-PCR. $h R B P 4$ was mainly expressed in the liver, testis, and lung, in which the mRbp4 gene was also expressed (Figure 2a). However, hRBP4 expression was lower in the brain and eyes and higher in the intestine and testis compared with the mRbp4 gene. Despite these differences, the tissue specificity of $h R B P 4$ expression was roughly similar to that of $m R b p 4$.

The expression levels of $m R b p 4$ - and hRBP4-encoding mRNA in $R b p 4^{+/+}, R b p 4^{+/ h R B P 4 o r f}$, and $R b p 4^{h R B P 40 \text { orfhRBP4orf }}$ mice were analyzed by northern blot analyses. As expected, mouse and human mRNAs were detected in the livers of $R b p 4^{+/ h R B P 4 o r f}$ mice, but only human mRNA was detected in the livers of $R b p 4^{h R B P 4 o r f / h R B P 4 o r f}$ mice (Figure 2b). The human mRNA level in Rbp4 $4^{h B P 4 \text { orf } h R B P 4 \text { orf }}$ mice was approximately twice that in $R b p 4^{+/ h R B P 4 o r f}$ mice.

As reported previously, ${ }^{20}$ serum levels of hTTR in $\operatorname{Ttr}^{h \text { TTRorf } / h T T R o r f}$ were lower than those in $\operatorname{Ttr}^{+/ h T T R o r f}$ because heterotetramers between hTTR and MTTR are more stable than the hTTR homotetramer. ${ }^{29}$ To determine whether the serum hRBP level is affected in the presence of mouse RBP4, the serum levels of the hRBP4 protein were compared in $R b p 4^{+/ h R B P 4 o r f}$ and $R b p 4^{h R B P 40 r f / h R B P 4 o r f}$ mice by western blot assay. In $R b p 4^{h R B P 4 o r f h R B P 4 o r f}$ mice, the hRBP4 serum level was roughly twice that in $R b p 4^{+/ h R B P 4 o r f}$ mice (Figure 2c). These results show that $h R B P 4$ was expressed in a dose-dependent manner in these mice.

\section{Rescue of Retinal Function in Rbp4 ${ }^{\text {hRBP4orf/hRBP4orf }}$ Mice}

A long-term ERG study was performed to analyze whether $R B P 40$ orf expression can rescue retinal function. Representative ERG waveforms are shown in Figure 3a.

As reported previously, ${ }^{15}$ the $\mathrm{a}$ - and b-wave amplitudes were significantly lower in $\mathrm{Rbp}^{-/-}$mice throughout the 40 week observation period (Figure $3 \mathrm{~b}$ ). In contrast, the a- and b-wave amplitudes in $R b p 4^{h R B P 4 o r f / h R B P 4 o r f}$ mice were almost normal (Figure $3 \mathrm{~b}$ ). Although there was a tendency for low amplitudes in $R b p 4^{h R B P 4 o r f h R B P 40 r f}$ mice, differences in these amplitudes between $R b p 4^{+/+}$and $R b p 4^{h R B P 4 o r f / h R B P 4 o r f}$ mice were not statistically significant. The a- and b-wave implicit times were longer in $\mathrm{Rbp}^{-/-}$mice at 7 weeks of age, but recovered to normal at 14 weeks of age (Figure $3 \mathrm{~b}$ ). This abnormality was not observed in $R b p 4^{h R B P 40 r f h R B P 4 o r f}$ mice (Figure 3b).

\section{Restoration of Retinal Histology in Rbp4 $4^{\text {RBP4orf/hRBP4orf }}$ Mice}

To analyze the morphological bases for normalized ERG, we performed histological analyses at 7 and 40 weeks of age. Retinal histology in each genotype at 7 weeks of age (Figure $4 a-c)$ was essentially the same as that at 40 weeks 
of age (Figure $4 \mathrm{~d}-\mathrm{f}$ ). As reported previously, ${ }^{15}$ various morphological defects were observed in the retinas from $R b p 4^{-/-}$mice, such as a thinner retina (Figure $4 \mathrm{~b}$ ). However, the retinas from $R b p 4^{h R B P 4 o r f / h R B P 4 o r f}$ mice (Figure 4c) showed almost no differences compared with the retinas from $\mathrm{Rbp4}^{+/+}$mice (Figure 4a).

a

ERG waveform

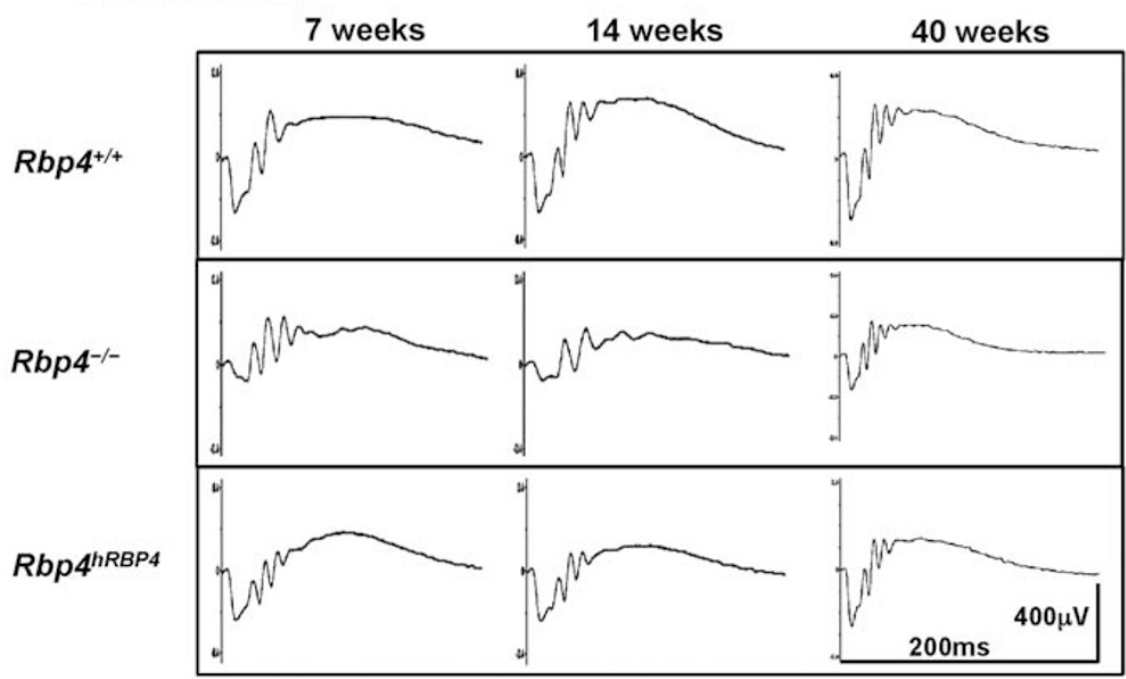

b ERG responses among mouse strains
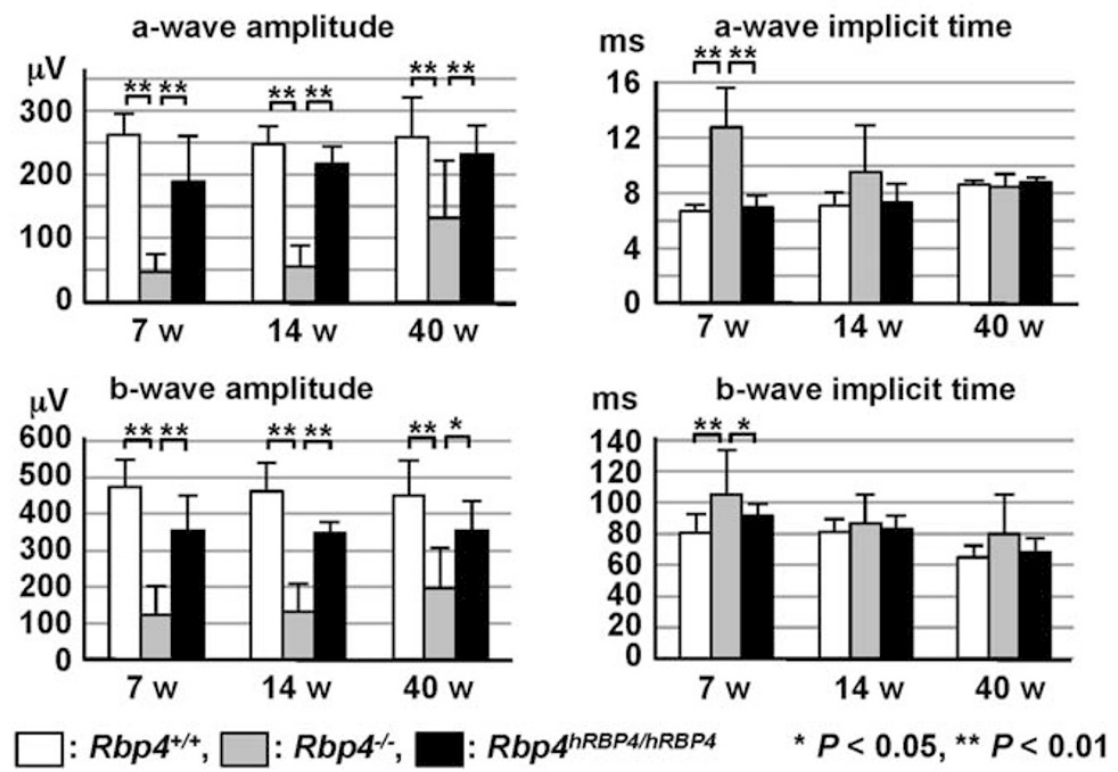

Figure 3 Rescue of retinal function in $R b p 4^{h R B P 4 / h R B P 4}$ mice. (a) ERG waveform. ERG responses in $R b p 4^{-/-}$mice recovered moderately at 40 weeks of age but were still lower than those in $R b p 4^{+/+}$and $R b p 4^{h R B P 4 / h R B P}$ mice. ERG responses in $R b p 4^{h R B P 4 / h R B P 4}$ mice were almost normal at all ages. (b) ERG responses among mouse strains. ERG responses in $R b p 4^{h R B P 4 / h R B P 4}$ mice were recovered to almost normal in all criteria. Data are presented as means $\pm \mathrm{s}$.d.

Figure 4 Restoration of retinal histology in $R b p 4^{\text {hRBP4/hRBP4 }}$ mice. Representative toluidine blue-stained retinal sections of 7 and 40 -week-old mice are shown. (a) Central retina from an $R b p 4^{+/+}$mouse. (b) Central retina from an $R b p 4^{-1-}$ mouse with a thinner retina. (c) Central retina from an Rbp4 ${ }^{\text {hRBP4/hRBP4 }}$ mouse. (d-f) Central retinas from mice at 7 weeks of age. (g-i) Central retinas from mice at 40 weeks of age. Histological abnormalities found in $R b p 4^{-/-}$mice were almost restored in $R b p 4^{h R B P 4 / h R B P 4}$ mice. GCL, ganglion cell layer; IPL, inner plexiform layer; INL, inner nuclear layer; OPL, outer plexiform layer; ONL, outer nuclear layer; IS, inner segments; OS, outer segments; RPE, retinal pigment epithelium; Ch, choroid; Sc, sclera. 

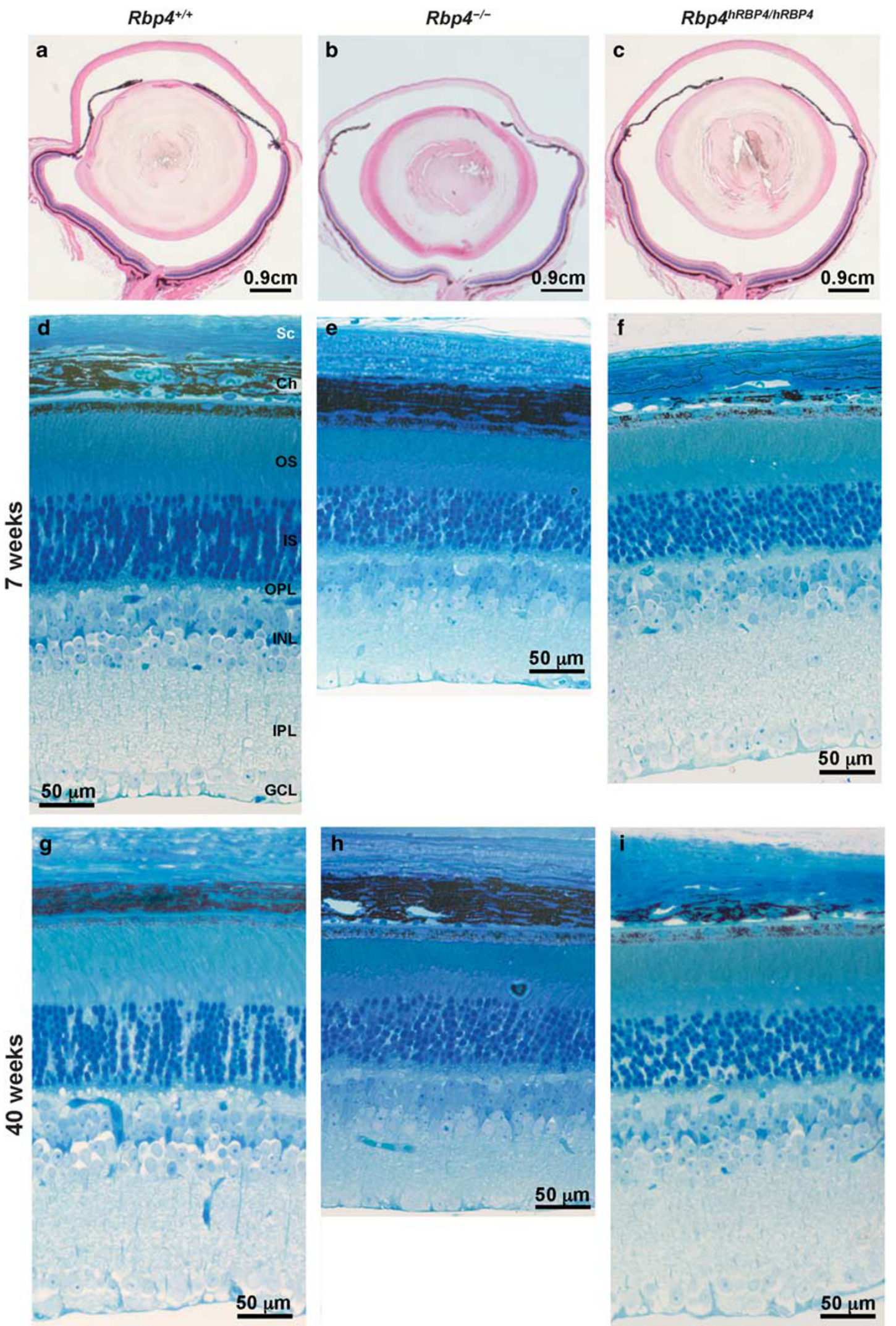


\section{Measurement of Retinal Properties}

For the precise evaluation of the $\mathrm{Rbp} 4^{-/-}$and $\mathrm{Rbp} 4^{\mathrm{hRBP} 4 \text { orf/hRBP4orf }}$ retinas, quantitative analyses of several retinal properties were conducted. The $R b p 4^{-/-}$retina showed normal retinal thickness (Figure $5 \mathrm{a}$ ), but reduced outer nuclear layer (ONL) thickness (Figure 5c). There were also tendencies toward reduced inner nuclear layer (INL) and outer segment (OS) thickness in $R b p 4^{h R B P 4 o r f / h R B P 4 o r f}$ (Figure $5 b$ and $d$ ). However, these differences were not statistically different, likely because of the considerable variation in retinal properties of $R b p 4^{-/-}$mice, as indicated by large s.d. values. In any case, the retinal properties in $R b p 4^{h R B P 4 \text { orf } / h R B P 4 \text { orf }}$ were restored to normal (Figure $5 \mathrm{a}-\mathrm{d}$ ).

\section{Transmission Electron Microscopy}

To analyze the retinal morphology more in detail, we performed TEM at 7 and 40 weeks of age. As in the histological analyses, the TEM data were essentially the same at 7 and 40 weeks of age; thus the data at 40 weeks of age are shown in Figure 6. The retina was thinner in a $R b p 4^{-/-}$mice (Figure $6 \mathrm{~b}$ and e) than in $R b p 4^{+/+}$mice (Figure $6 \mathrm{a}$ and $\mathrm{d}$ ). The distance between the inner limiting membrane and outer plexiform layer (OPL) in $R b p 4^{-1-}$ mice (Figure $6 \mathrm{~b}$ ) was much shorter than that in $R b p 4^{+/+}$(Figure 6a) or $R b p 4^{h R B P 4 o r f / h R B P 4 o r f}$ (Figure 6c) mice, with fewer retinal ganglion cells (Figure 6b). In the inner plexiform layer (IPL), bipolar axons, amacrine dendrites and ganglion cell dendrites were fewer in one $R b p 4^{-/-}$mice (Figure 6h) than in $R b p 4^{+/+}$ (Figure $6 \mathrm{~g}$ ) or Rbp $4^{h R B P 4 o r f / h R B P 4 o r f}$ mice (Figure 6i). The electron density in the OPL (a layer of neuronal synapses) was very low in $R b p 4^{-1-}$ mice (Figure 6k) compared with $R b p 4^{+/+}$(Figure 6j) or $R b p 4^{h R B P 4 o r f / h R B P 4 o r f}$ (Figure 6l) mice. The Golgi apparatus was swollen in photoreceptor cell of $R b p 4^{-/-}$(Figure 6n), but not in $R b p 4^{+/+}$(Figure $6 \mathrm{~m}$ ) or $R b p 4^{h R B P 4 o r f / h R B P 4 o r f}$ (Figure 6o) mice. Although the number of mitochondria in photoreceptor cell was similar among three strains, there were very few cristae in $R b p 4^{-1-}$ mice (Figure 6q) compared with $R b p 4^{+/+}$(Figure $6 \mathrm{p}$ ) or $R b p 4^{h R B P 4 o r f / h R B P 4 o r f}$
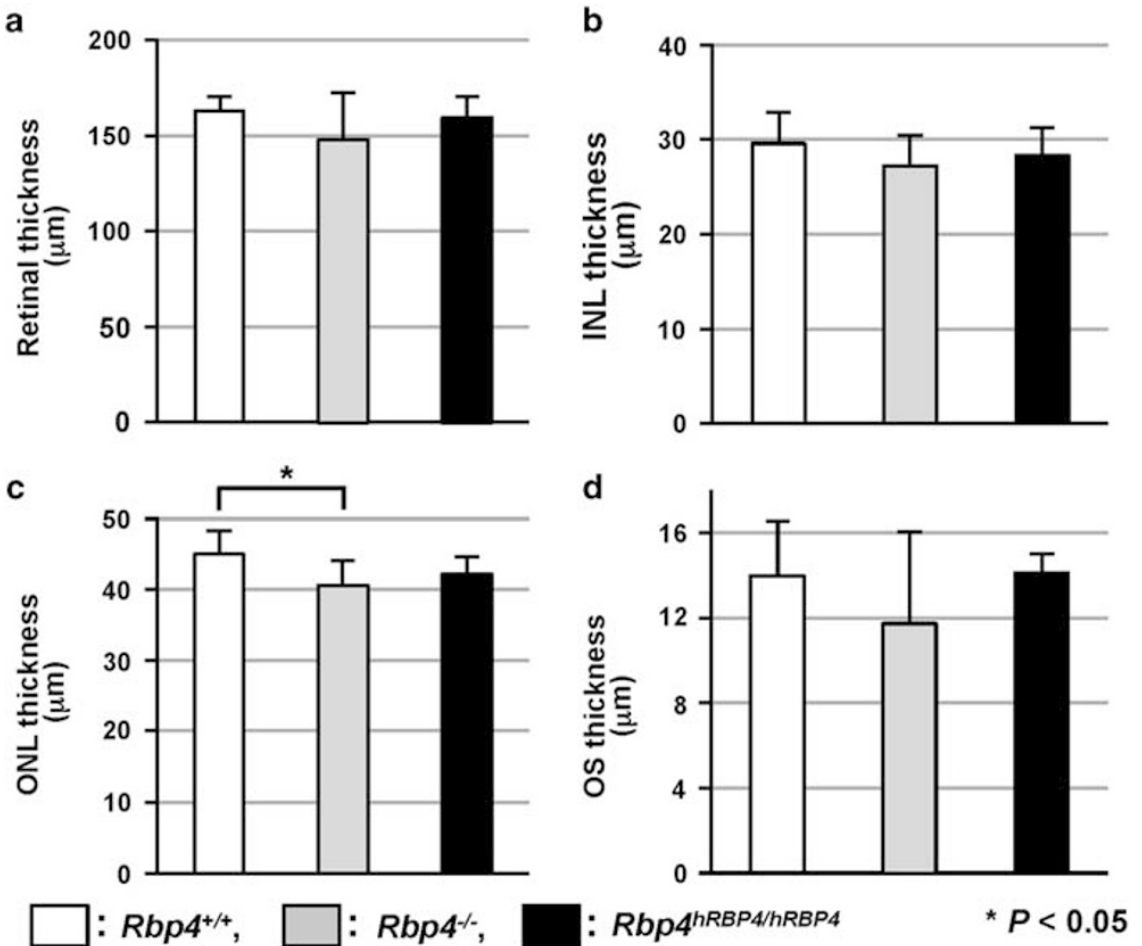

Figure 5 Measurement of retinal properties. (a) Retinal thickness from GCL to OSL. (b) INL thickness. The INL thickness was significantly decreased in the $R b p 4^{-1-}$ mice. (c) ONL thickness. (d) OS thickness. There was a tendency towards reduced INL and OS thickness in $R b p 4^{h R B P 4 / h R B P 4}$ mice. Data are presented as means \pm s.d.

Figure 6 TEM. (a-c) GCL to INL. The distance between the inner limiting membrane and the OPL was much shorter in $R b p 4^{-/-}$mice (b). (d-f) ONL to Sc. An $R b p 4^{-/-}$mouse showed losses of the ONL and the IS/OS (e). (g-i) IPL. Fewer synapses were found in the IPL (g). (j-I) INL and OPL. The electron density in the OPL (surrounded by a white line) was very low (j). (m-o) Golgi apparatus in a photoreceptor cell. The Golgi apparatus (arrow) was swollen in $R b p 4^{-1-}$ mice (n). (p-r) Mitochondria in a photoreceptor cell. There were very few cristae in $R b p 4^{-1-}$ mice (q). Abnormalities found in an $R b p 4^{-1-}$ mouse were almost completely restored in an $R b p 4^{h R B P 4 / h R B P 4}$ mouse. $\mathrm{GCL}$, ganglion cell layer; IPL, inner plexiform layer; INL, inner nuclear layer; OPL, outer plexiform layer; ONL, outer nuclear layer; IS, inner segments; OS, outer segments; RPE, retinal pigment epithelium; Ch, choroid; Sc, sclera. 

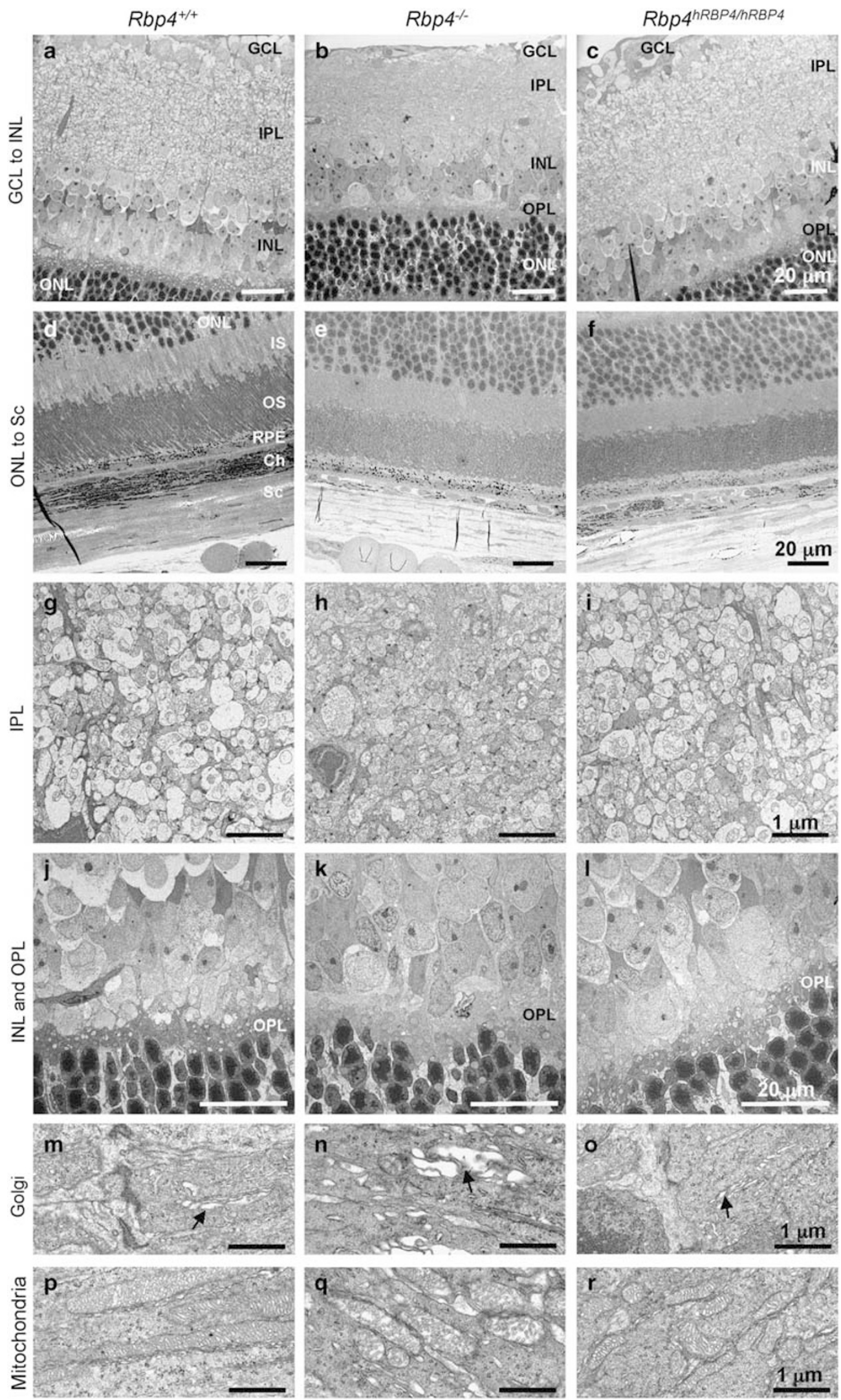

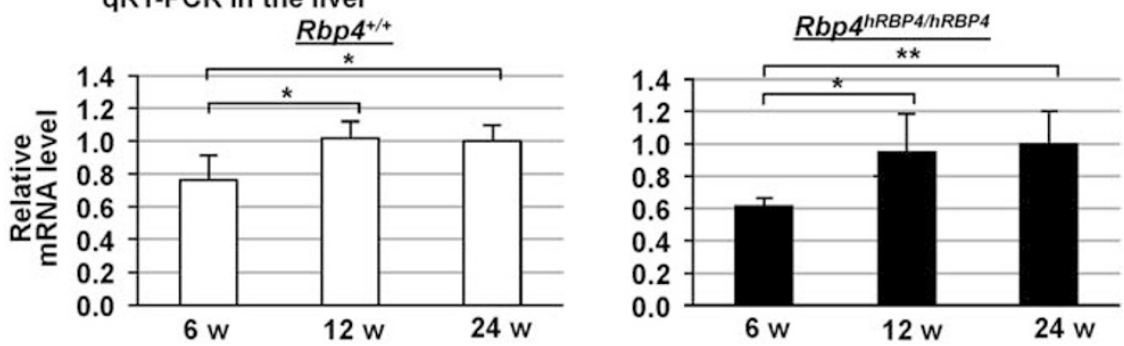

b

qRT-PCR in the eyes
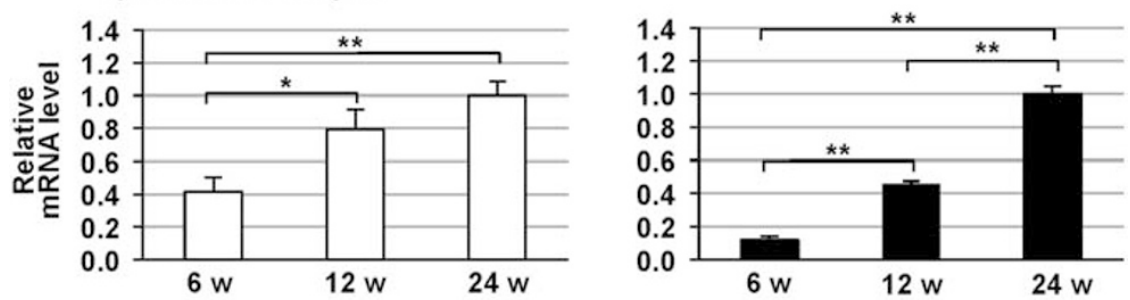

C

Serum RBP4 (ELISA)
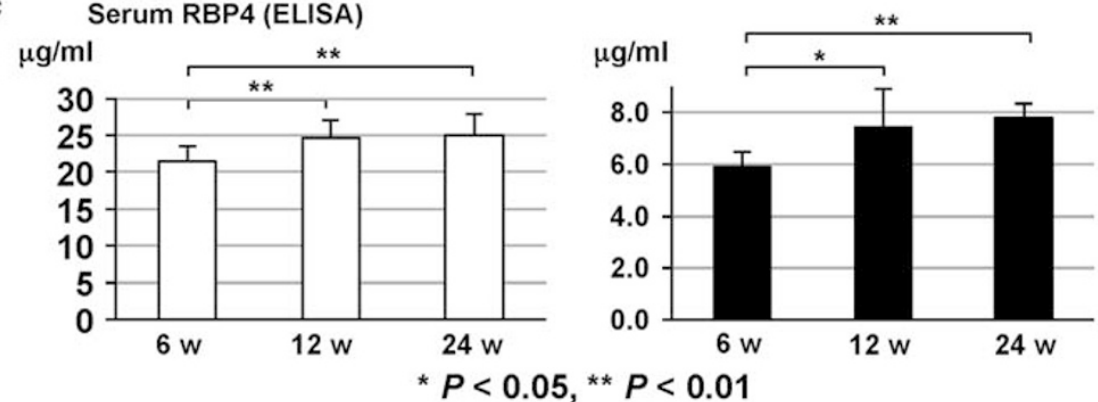

Figure 7 Temporal expression of mRbp4 and hRBP4. The expression level at 24 weeks of age was set as 1.0 in all the experiments. (a) Expression in liver. (b) Expression in eyes. (c) Serum levels of mRbp4 and hRBP4. The mRbp4 and hRBP4 expression profiles in the liver and serum were similar, while hRBP4 expression levels in the eyes were lower at 6 and 12 weeks of age. Data are presented as means \pm s.d.

(Figure 6r) mice. Overall, the TEM abnormalities observed in $R b p 4^{-/-}$were not found in $R b p 4^{h R B P 4 o r f / h R B P 4 o r f}$ mice.

\section{Temporal Expression of Rbp4 and hRBP4}

As the retinal phenotypes were already rescued at 7 weeks of age, we analyzed the temporal expression of $m R b p 4$ and $h R B P 4$. RNAs extracted from the liver and eyes was used in qRT-PCR analyses. In the liver, the $m R b p 4$ levels at 6 and 12 weeks of age were 76 and $102 \%$ of the level (100\%) at 24 weeks (Figure 7a, left), and the $h R B P 4$ levels at 6 and 12 weeks were 61 and $95 \%$ of the level at 24 weeks (Figure $7 \mathrm{a}$, right). For $m R b p 4$ and $h R B P 4$, there were significant differences in expression between 6 and 12 weeks and between 6 and 24 weeks, but not between 12 and 24 weeks. These data suggest that mRbp4 and hRBP4 have similar temporal expression patterns and that the levels of $m R b p 4$ and human $R B P 4$ reached a maximum at approximately 12 weeks of age.

In the eyes, the $m R b p 4$ levels at 6 and 12 weeks were 42 and $79 \%$ compared with that at 24 weeks (Figure $7 \mathrm{~b}$, left). There was a significant difference in expression between 6 and 12 and 6 and 24 weeks, but not between 12 and 24 weeks. In contrast, the $h R B P 4$ levels at 6 and 12 weeks were 12 and $45 \%$ compared with that at 24 weeks (Figure $7 \mathrm{~b}$, right), with significant differences between 6 and 12 weeks, 12 and 24 weeks, and 6 and 24 weeks. These results suggested that $m R b p 4$ reached a maximum level at 12 weeks, whereas $h R B P 4$ expression was very low at 6 weeks and increased gradually up to 24 weeks.

At 6, 12, and 24 weeks of age, the serum mRBP4 levels in $R b p 4^{+/+}$mice were $21.5 \pm 2.03,24.7 \pm 2.37$, and $25.0 \pm 2.94 \mu \mathrm{g} / \mathrm{ml}$ (Figure 7c, left) and those of hRBP4 in $R b p 4^{h R B P 4 / h R B P 4}$ mice were $5.9 \pm 0.55,7.4 \pm 1.50$, and $7.8 \pm 0.53 \mu \mathrm{g} / \mathrm{ml}$ (Figure 7c, right). Thus, the hRBP4 levels in $R b p 4^{h R B P 4 / h R B P 4}$ mice at 6,12 , and 24 weeks were $27 \%$, $30 \%$, and $31 \%$, respectively, compared with those of mRBP4 in $\mathrm{Rbp4}^{+/+}$mice. For mRBP4 and hRBP4, there were significant differences in expression between 6 and 12 and 6 and 24 weeks, but not between 12 and 24 weeks. These results are consistent with the RNA expression levels in the liver, with $m R b p 4$ and $h R B P 4$ expression both reaching maxima at 12 weeks. 


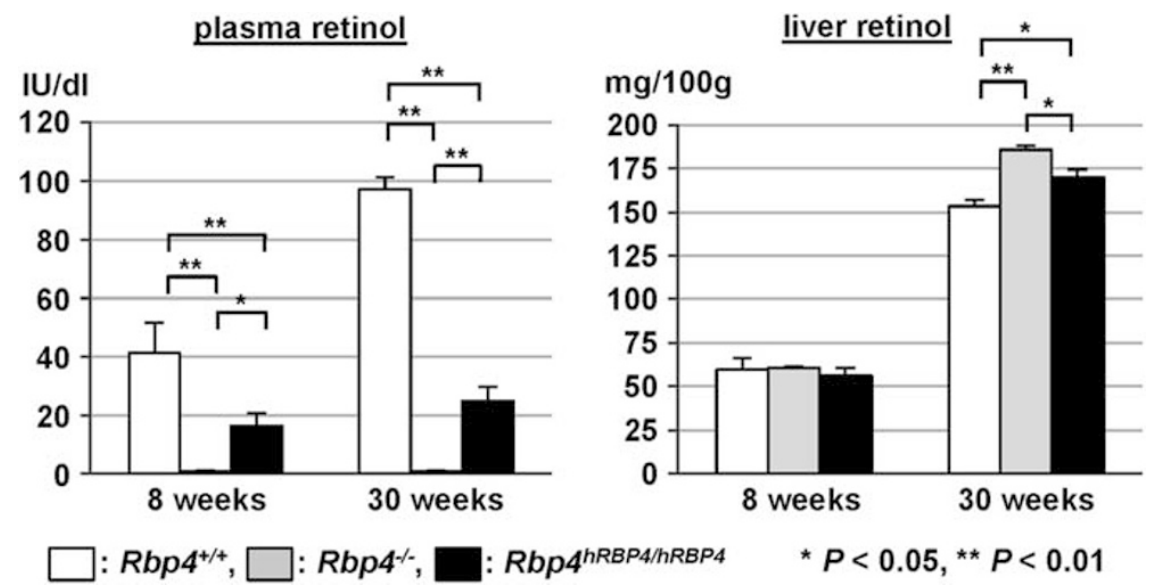

Figure 8 Retinol levels in the plasma and liver. In Rbp4 ${ }^{\text {hRBP4/hRBP4 }}$ mice, the plasma retinol levels were lower at 8 and 30 weeks of age. In liver, retinol accumulated in all strains, but the amount of retinol was the largest in $R b p 4^{-/-}$mice and the lowest in $R b p 4^{+/+}$mice. Data are presented as means \pm s.d.

\section{Retinol Levels in the Plasma and Liver}

Previously, we showed that plasma retinol levels were below the detection threshold $(<5 \mathrm{IU} / \mathrm{dl})$, whereas liver retinol levels were increased in $R b p 4^{-/-}$mice. ${ }^{15}$ To examine the retinol status in $R b p 4^{h R B P 40 \text { orfhRBP4orf }}$ mice, retinol levels in the plasma and liver from $R b p 4^{+/+}, R b p 4^{-/-}$, and $R b p 4^{h R B P 4 o r f h R B P 4 o r f}$ mice were determined. The plasma levels of retinol in these mice were $41.3 \pm 10.1,<5$, and $16.3 \pm 4.2 \mathrm{IU} / \mathrm{dl}$, respectively, at 8 weeks of age, and $97 \pm 4.4$, $<5$, and $24.7 \pm 5.1 \mathrm{IU} / \mathrm{dl}$, respectively, at 30 weeks (Figure 8 , left). Thus, in $R b p 4^{h R B P 4 o r f / h R B P 4 \text { orf }}$ mice, the plasma retinol levels were $39 \%$ and $25 \%$ of those in $R b p 4^{+/+}$mice at 8 and 30 weeks, respectively.

The liver retinol levels in $R b p 4^{+/+}, R b p 4^{-/-}$, and $R b p 4^{h R B P 4 o r f / h R B P 4 o r f}$ mice were $59.5 \pm 6.5,60.6 \pm 0.6$, and $55.9 \pm 4.7 \mathrm{mg} / 100 \mathrm{~g}$, respectively, at 8 weeks and $153.3 \pm 3.5$, $185.7 \pm 2.5$, and $169.7 \pm 5.0 \mathrm{mg} / 100 \mathrm{~g}$, respectively, at 30 weeks (Figure 8, right). Thus, at 8 weeks, the liver retinol levels were similar in the three strains, which indicated that the low plasma retinol level did not affect hepatic retinol stores. The liver retinol level at 30 weeks was highest in $R_{p p 4^{-1-}}$, followed by $R b p 4^{h R B P 4 o r f h R B P 4 o r f}$ and $R b p 4^{+/+}$mice.

\section{Expression of TTR and RBP4 in Liver and Serum}

To examine whether mTTR expression in liver or serum was altered in $R b p 4^{+/+}, R b p 4^{-/-}$and $R b p 4^{h R B P 4 o r f / h R B P 4 o r f}$ mice, northern blot and western blot analyses were performed. As shown in Figure 9a, the mRNA and protein levels of mTTR in liver were similar among these strains. We also measured the mRBP4 or hRBP4 level in liver of $R b p 4^{+/+}$or $R b p 4^{h R B P 40 r f / h R B P 4 o r f}$ mice, respectively. The observed concentrations were $32.9 \pm 1.2 \mathrm{mg} / \mathrm{g}$ protein and $10.6 \pm 0.38 \mathrm{mg} / \mathrm{g}$ protein, respectively. These data are consistent with those for serum RBP4 concentrations. Namely, human RBP4 levels in $R b p 4^{h R B P 4 o r f / h R B P 4 o r f}$ mice were one-third of the RBP4 levels in $R b p 4^{+/+}$mice. In addition, the serum levels of mTTR were also found to be similar among these strains as
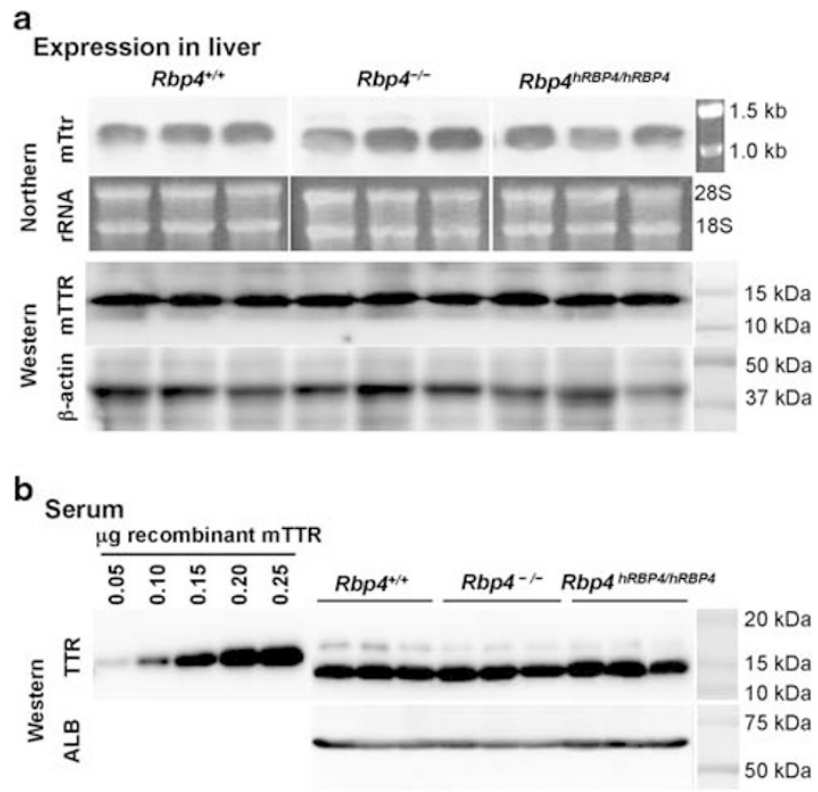

Figure 9 Expression of $\mathrm{mTTR}$ in liver and serum. (a) Expression in liver. Northern blot and western blot analyses showed similar expression levels in all strains. (b) Serum mTTR expression. Western blot analysis showed similar levels of expression in all the strains.

demonstrated by western blot analyses (Figure 9b). At 12 weeks, the serum levels in $R b p 4^{+/+}, R_{b p} 4^{-/-}$, and $R b p 4^{h R B P 40 r f / h R B P 40 \text { rf }}$ mice were $306 \pm 10.2,306 \pm 5.8$, and $305 \pm 4.8 \mu \mathrm{g} / \mathrm{ml}$, respectively. There were no significant differences observed for these levels among mouse strains (Figure 9b). Taken together, these results suggest that mTTR expression was not affected in $R b p 4^{-/-}$and $R b p 4^{h R B P 40 \text { rf } h R B P 4 o r f}$ mice.

\section{Gel Filtration Chromatography}

$R b p 4^{+/+}$and $R b p 4^{h R B P 4 \text { orf } / h R B P 4 o r f}$ plasma samples were subjected to gel filtration chromatography, and column fractions 


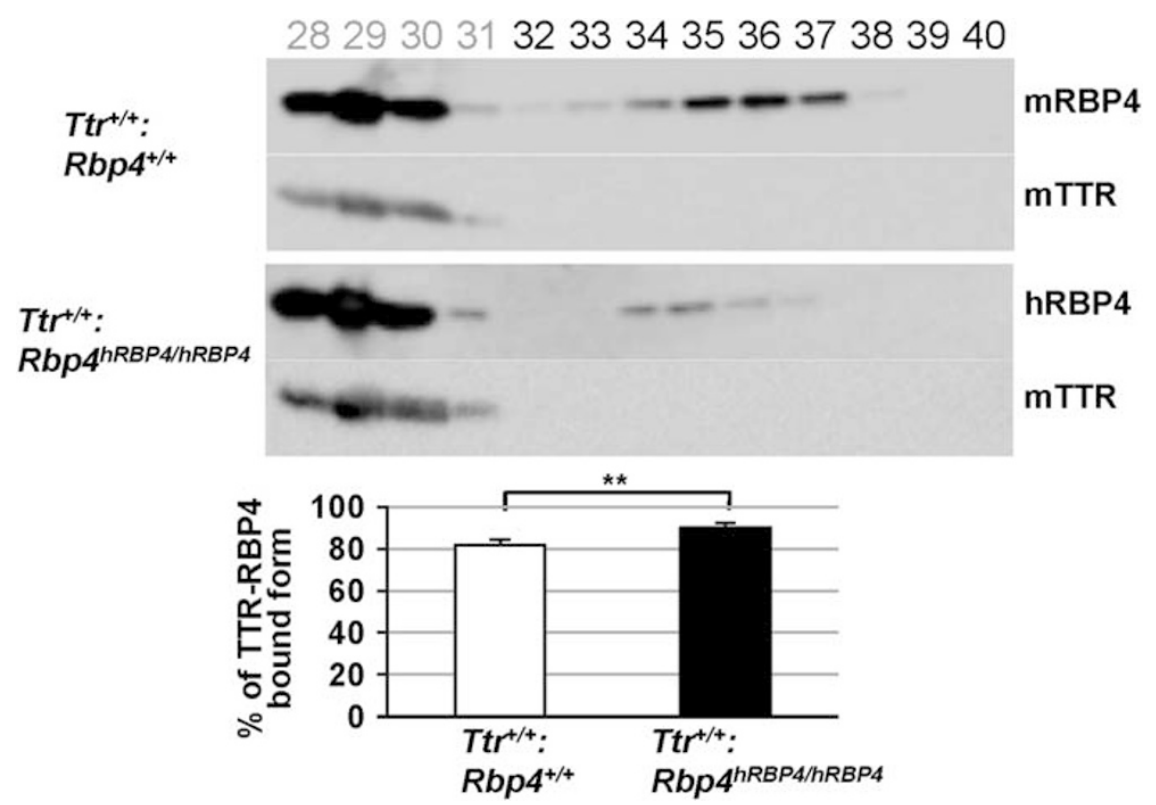

Figure 10 Gel filtration chromatography. Each fraction was analyzed by western blotting using anti-RBP4 and TTR antibodies. The bound form of RBP4 and TTR was found in fractions 28-31, whereas the free form of RBP4 was found in fractions 32-39. The percentage of the TTR-RBP4 bound form in $R b p 4^{h R B P 4 / h R B P 4}$ mice was higher than in $R b p 4^{+/+}$mice. ${ }^{* *} P<0.01$.

were analyzed by western blotting. The majority of immunoreactive RBP4 and TTR eluted together in fractions 28 to 31 in both the strains. A small amount of immunoreactive RBP4 eluted after this primary peak in subsequent fractions 32 to 39 (Figure 10). These secondary fractions represent non-TTR-bound RBP4 because no associated TTR immunoreactivity was observed. The percentage of the TTR-RBP4 bound form in $R b p^{h R B P 40 r f / h R B P 4 o r f}$ mice $(90.1 \pm 1.8)$ was higher than in $R b p 4^{+/+}$mice $(82.0 \pm 2.2$; Figure 10). Although these results suggest that the affinity of hRBP4 for mouse TTR was slightly higher than mRBP4 for mTTR, this could be due to the lower hRBP4 concentration than the mRBP4 concentration.

\section{Rd8 Mutation}

As reported by Mattapallil et al, ${ }^{27}$ the $r d 8$ mutation in the $\mathrm{Crb} 1$ gene was detected in the $\mathrm{C} 57 \mathrm{BL} / 6 \mathrm{~N}$ substrain, but not in the C57BL/6J substrain. This mutation results in ocular spots and retinal lesions such as retinal folding, dysplasia of the nuclear layers, retinal degeneration, and vacuolation of the retinal pigment epithelium. ${ }^{27,28}$ To rule out the possibility that $R b p 4^{h R B P 4 / h R B P 4}$ mice carried the $r d 8$ mutation, we analyzed this mutation in our mice. We confirmed that none of the mice used in our morphological and functional analyses of the retina had the $r d 8$ mutation (Supplementary Figure S2).

\section{DISCUSSION}

In this study, we established the mouse strain, $R b p 4^{h R B P 4 o r f / h R B P 40 \text { rf }}$ mouse strain with a normal human RBP4orf at the mouse Rbp4 locus. As the serum hRBP4 levels in $R b p 4^{h R B P 40 \text { rffhRBP4orf }}$ mice were approximately $30 \%$ of those of mRBP4 in $R b p 4^{+/+}$mice, we used this mouse strain to examine whether this level of hRBP4 expression can rescue phenotypes observed in $\mathrm{Rbp}^{-/-}$mice. This result will provide valuable information regarding gene therapy for single-gene disorders such as inborn errors of metabolism. Indeed, the retinal impairment and morphological abnormalities observed in $\mathrm{Rbp}^{-/-}$mice were almost completely rescued in $R b p 4^{h R B P 4 o r f / h R B P 40 r f}$ mice.

The hRBP4orf with a PGK-puro cassette was inserted into the mouse endogenous Rbp4 gene locus. The hRBP4orf in the replaced allele was expressed in similar tissues, including the liver, testis, and lung, as those for the $m R b p 4$ gene with different expression levels in some tissues. Temporal expression patterns of $m R b p 4$ and $h R B P 4$ were similar in the liver. However, in the eyes, $h R B P$ expression was low at 6 and 12 weeks of age but increased substantially at 24 weeks. The reasons for the moderately altered expression patterns are unclear, but the integration of hRBP4 with a PGK-puro cassette may affect the spatial, temporal, and quantitative expression of $h R B P 4$ in the replaced allele.

The plasma retinol level in $R b p 4^{R B P 4 o r f / R B P 4 o r f}$ mice was approximately one-third or one-fourth of that in $R b p 4^{+/+}$ mice at 8 or 30 weeks of age, respectively. Interestingly, the plasma retinol level increased with age both in $R b p 4^{+/+}$and $R b p 4^{R B P 4 o r f / R B P 4 o r f}$ mice, although the increase rate in $R b p 4^{R B P 4 o r f / R B P 4 o r f}$ mice was much smaller than that in $R b p 4^{+/+}$mice. The liver retinol concentrations at 8 weeks of age were similar in both $R b p 4^{+/+}$mice and $R b p 4^{R B P 4 o r f / R B P 4 o r f}$ mice. In contrast, the liver retinol concentrations in $R b p 4^{R B P 4 o r f / R B P 4 o r f}$ mice were higher than those in $R b p 4^{+/+}$ 
mice, suggesting that low hRBP4 expression resulted in high liver retinol concentrations. In any case, these findings are consistent with the fact that the plasma RBP4 concentrations in $R b p 4^{R B P 4 o r f / R B P 4 o r f}$ mice were lower than those in $R b p 4^{+/+}$mice.

The $R b p 4^{-/-}$mice showed a severe impairment of retinal function and morphological abnormalities. However, our Rbp4 $4^{h R P \text { Aorf } h R B P 4 o r f}$ mice had almost normal ERG responses and retinal morphologies. Retinal impairment could be caused by either the loss of Rbp4 expression in the eyes or retinol deficiency in the blood. In the eyes, the level of human RBP4 at 6 weeks was $12 \%$ compared with that at 24 weeks. Nevertheless, ERG and histology were almost normal in $R b p 4^{h R B P 4 o r f h R B P 4 o r f}$ mice at 7 weeks of age. This finding suggests that Rbp4 expression in the eyes does not have an important role in visual function. Quadro et a ${ }^{30}$ generated a transgenic mouse strain (hRBP4: $\mathrm{mRbp}^{-{ }^{-1}}$ ) that expressed hRBP4 under the control of the muscle creatine kinase promoter on an $R b p 4^{-1-}$ background. Although no hRBP4 was detected in the retinal pigment epithelium of hRBP4: $\mathrm{mRbp}^{-/-}$mice, a normal ERG profile was observed in the eyes. As plasma retinol levels were normal, circulating RBP4 efficiently delivered retinol to the eye. Thus, the ocular phenotypes in our $R b p 4^{-1-}$ mice may be rescued by expression of $h R B P 4$ in the liver, which resulted in retinol delivery to the eyes. In other words, circulating retinol may restore morphological abnormalities and result in the rescue of retinal function.

Similar rescue experiments have been performed using knockout mouse models. ${ }^{31-33}$ Mpv17 mice, a model of glomerulosclerosis, that expressed the human MVP17 gene showed normal glomerular histology. ${ }^{32}$ In human $p 25$ (C-terminal truncation product of $p 35$ ) transgenic mice with a Cdk activator protein p35-null background, brain anatomy (ie, loss of the laminar structure within the cerebral cortex) was partially rescued. ${ }^{31}$ Furthermore, a 130-kilobase (kb) yeast artificial chromosome containing the human SCL (stem cell leukemia) locus completely rescued the embryonic lethal phenotype of $\mathrm{Sc}^{1-}$ mice. ${ }^{33}$ However, in these cases, the expression levels of transgenes $v s$ mouse endogenous genes were not clearly demonstrated. There is little data on how much expression is required to rescue phenotypes in human recessively inherited diseases. Our results suggest that the $30 \%$ expression of $h R B P 4$ in the liver is sufficient to rescue phenotypes caused by the Rbp4 mutation in our mouse model, similar to human patients.

Supplementary Information accompanies the paper on the Laboratory Investigation website (http://www.laboratoryinvestigation.org)

\section{ACKNOWLEDGMENTS}

We thank Kyoko Ikeda and Shundan Jin for their assistance with eye morphological and functional analyses. This work was supported by a Grantin-Aid for Scientific Research (C) (Grant number 24590404; Japan Society for the Promotion of Science to ZL), and Grant-in-Aid for Scientific Research (S) (Grant number 21220010; Japan Society for the Promotion of Science), Scientific Support Programs for Cancer Research Grant-in-Aid for Scientific Research on Innovative Areas (Grant number 22150001; Ministry of Education, Culture, Sports, Science and Technology), CREST (JST), and a research grant from TransGenic (to KY).

\section{DISCLOSURE/CONFLICT OF INTEREST}

The authors declare no conflict of interest.

1. D'Onofrio C, Colantuoni V, Cortese R. Structure and cell-specific expression of a cloned human retinol binding protein gene: the 5 '-flanking region contains hepatoma specific transcriptional signals. EMBO J 1985;4:1981-1989.

2. Laurent $\mathrm{BC}$, Nilsson $\mathrm{MH}$, Bavik $\mathrm{CO}$, et al. Characterization of the rat retinol-binding protein gene and its comparison to the threedimensional structure of the protein. J Biol Chem 1985;260: 11476-11480.

3. Soprano DR, Soprano KJ, Goodman DS. Retinol-binding protein messenger RNA levels in the liver and in extrahepatic tissues of the rat. J Lipid Res 1986;27:166-171.

4. Davis JT, Ong DE. Synthesis and secretion of retinol-binding protein by cultured rat Sertoli cells. Biol Reprod 1992;47:528-533.

5. Davis JT, Ong DE. Retinol processing by the peritubular cell from rat testis. Biol Reprod 1995;52:356-364.

6. Jaworowski A, Fang Z, Khong TF, et al. Protein synthesis and secretion by cultured retinal pigment epithelia. Biochim Biophys Acta 1995;1245: 121-129.

7. Ong DE, Davis JT, O'Day WT, et al. Synthesis and secretion of retinolbinding protein and transthyretin by cultured retinal pigment epithelium. Biochemistry 1994;33:1835-1842.

8. Soprano DR, Blaner WS. Plasma retinol-binding protein. In: Sporn MB, Roberts AB, Goodman DS (eds). The Retinoids: Biology, Chemistry, and Medicine, 2nd edn. Raven Press: New York, NY, USA, 1994, pp 257-281.

9. Goodman DS. Plasma Retinol-Binding Protein. Academic Press: New York, NY, USA, 1984.

10. Wolf G. The discovery of the visual function of vitamin A. J Nutr 2001;131:1647-1650.

11. Cukras $C$, Gaasterland $T$, Lee $P$, et al. Exome analysis identified a novel mutation in the RBP4 gene in a consanguineous pedigree with retinal dystrophy and developmental abnormalities. PLoS One 2012;7:e50205.

12. Seeliger MW, Biesalski HK, Wissinger $B$, et al. Phenotype in retinol deficiency due to a hereditary defect in retinol binding protein synthesis. Invest Ophthalmol Vis Sci 1999;40:3-11.

13. Quadro L, Blaner WS, Salchow DJ, et al. Impaired retinal function and vitamin A availability in mice lacking retinol-binding protein. EMBO J 1999;18:4633-4644.

14. Quadro L, Blaner WS, Hamberger $L$, et al. Muscle expression of human retinol-binding protein (RBP). Suppression of the visual defect of RBP knockout mice. J Biol Chem 2002;277:30191-30197.

15. Shen J, Shi D, Suzuki T, et al. Severe ocular phenotypes in Rbp4deficient mice in the C57BL/6 genetic background. Lab Invest 2016;96: 680-691.

16. Berni R, Malpeli G, Folli $C$, et al. The lle-84->Ser amino acid substitution in transthyretin interferes with the interaction with plasma retinol-binding protein. J Biol Chem 1994;269:23395-23398.

17. Episkopou V, Maeda S, Nishiguchi S, et al. Disruption of the transthyretin gene results in mice with depressed levels of plasma retinol and thyroid hormone. Proc Natl Acad Sci USA 1993;90: 2375-2379.

18. Melhus $\mathrm{H}$, Nilsson $\mathrm{T}$, Peterson PA, et al. Retinol-binding protein and transthyretin expressed in HeLa cells form a complex in the endoplasmic reticulum in both the absence and the presence of retinol. Exp Cell Res 1991;197:119-124.

19. Wei $S$, Episkopou V, Piantedosi $R$, et al. Studies on the metabolism of retinol and retinol-binding protein in transthyretin-deficient mice produced by homologous recombination. J Biol Chem 1995;270: 866-870.

20. Zhao G, Li Z, Araki K, et al. Inconsistency between hepatic expression and serum concentration of transthyretin in mice humanized at the transthyretin locus. Genes Cells 2008;13:1257-1268. 
21. Yagi T, Tokunaga $T$, Furuta $Y$, et al. A novel ES cell line, $\Pi T 2$, with high germline-differentiating potency. Anal Biochem 1993;214:70-76.

22. Araki K, Imaizumi T, Okuyama K, et al. Efficiency of recombination by Cre transient expression in embryonic stem cells: comparison of various promoters. J Biochem 1997;122:977-982.

23. Li Z, Zhao G, Shen J, et al. Enhanced expression of human cDNA by phosphoglycerate kinase promoter-puromycin cassette in the mouse transthyretin locus. Transgenic Res 2011;20:191-200.

24. Sato $H$, Suzuki T, lkeda $K$, et al. A monogenic dominant mutation in Rom1 generated by $\mathrm{N}$-ethyl-N-nitrosourea mutagenesis causes retinal degeneration in mice. Mol Vis 2010;16:378-391.

25. Notsumoto S, Kobayashi K, Hirauchi K, et al. Determination of retinol in serum by high-performance liquid chromatograpgy with fluorometric detection using a column-switching system. Clin Chem 1993;22: 190-194.

26. Thompson LB, Schimpf KJ, Stiner LA, et al. Determination of vitamin A (retinol) in infant and medical nutritional formulas with AOAC method 992.06 using a modified extraction procedure: single-laboratory validation. J AOAC Int 2010;93:1523-1529.

27. Mattapallil MJ, Wawrousek EF, Chan CC, et al. The Rd8 mutation of the Crb1 gene is present in vendor lines of $\mathrm{C} 57 \mathrm{BL} / 6 \mathrm{~N}$ mice and embryonic stem cells, and confounds ocular induced mutant phenotypes. Invest Ophthalmol Vis Sci 2012;53:2921-2927.

28. Mehalow AK, Kameya S, Smith RS, et al. CRB1 is essential for external limiting membrane integrity and photoreceptor morphogenesis in the mammalian retina. Hum Mol Genet 2003;12:2179-2189.

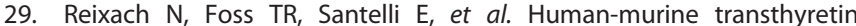
heterotetramers are kinetically stable and non-amyloidogenic: a lesson in the generation of transgenic models of diseases involving oligomeric proteins. J Biol Chem 2007;283:2098-2107.

30. Quadro L, Hamberger L, Colantuoni V, et al. Understanding the physiological role of retinol-binding protein in vitamin A metabolism using transgenic and knockout mouse models. Mol Aspects Med 2003;24:421-430.

31. Patzke $H$, Maddineni $U$, Ayala $R$, et al. Partial rescue of the p35-/brain phenotype by low expression of a neuronal-specific enolase p25 transgene. J Neurosci 2003;23:2769-2778.

32. Schenkel J, Zwacka RM, Rutenberg $C$, et al. Functional rescue of the glomerulosclerosis phenotype in Mpv17 mice by transgenesis with the human Mpv17 homologue. Kidney Int 1995:48:80-84.

33. Sinclair AM, Bench AJ, Bloor AJ, et al. Rescue of the lethal $\mathrm{scl}(-/-)$ phenotype by the human SCL locus. Blood 2002;99:3931-3938. 